\title{
Nonerosive Reflux Disease (NERD) - An Update
}

\author{
Tiberiu Hershcovici, M.D. and Ronnie Fass, M.D.*
}

The Neuroenteric Clinical Research Group, Section of Gastroenterology, Southern Arizona VA Health Care System, Tucson, Arizona, USA

Recognizing nonerosive reflux disease (NERD) as a distinct presentation of gastroesophageal reflux disease (GERD) was one of the most important developments in the field of GERD in the last decade. Whilst the definition of NERD has not changed significantly over the years, the disorder accounts for the majority of the GERD patients and those who failed proton pump inhibitor (PPI) treatment. Recent developments in NERD focused primarily on understanding the pathophysiology and natural history. The introduction of esophageal impedance $+\mathrm{pH}$ has led to the assessment of other forms of gastroesophageal reflux in causing NERD. Therapeutic modalities still focus on acid suppression, but there is growing recognition that other therapeutic strategies should be considered in NERD.

(J Neurogastroenterol Motil 2010;16:8-21)

\section{Key Words}

Nonerosive reflux disease, Gastroesophageal reflux disease, Proton pump inhibitor

\section{Introduction}

It has been demonstrated that $44 \%$ of the US population report gastroesophageal reflux disease (GERD)-related symptoms at least once a month and $20 \%$ once a week. ${ }^{1,2}$ Furthermore, due to the close relationship between GERD and body mass index (BMI), it is highly likely that the prevalence of GERD will closely follow the increase in BMI that is expected in the future.

Most of the patients with GERD fall into 1 of 2 categories: nonerosive reflux disease (NERD) or erosive esophagitis. The 2 main phenotypes of GERD appear to have different pathophysiological and clinical characteristics. Furthermore, NERD and erosive esophagitis clearly diverge when it comes to response to antireflux treatment. NERD patients have a significantly lower response rate to proton pump inhibitor (PPI) therapy, and consequently they constitute the majority of the refractory heartburn group. ${ }^{3,4}$

\section{Definition}

NERD has been commonly defined as the presence of classic GERD symptoms in the absence of esophageal mucosal injury during upper endoscopy. The Genval workshop suggested that the definition of NERD should be reserved for individuals who satisfy the definition of GERD but who do not have either Barrett's esophagus or definite endoscopic esophageal mucosal breaks (erosion or ulceration). ${ }^{5}$ We proposed that NERD should

Received: December 24th, 2009 Accepted: December 30th, 2009

(c) This is an Open Access article distributed under the terms of the Creative Commons Attribution Non-Commercial License (http://creativecommons. org/licenses/by-nc/3.0) which permits unrestricted non-commercial use, distribution, and reproduction in any medium, provided the original work is properly cited.

*Correspondence: Ronnie Fass, M.D., FACP, FACG

Chief of Gastroenterology, Southern Arizona VA Health Care System, GI Section (1-111G-1), 3601 S. 6 th Avenue, Tucson, AZ 85723-0001, USA

Financial support: None.

Tel: +1-520-792-1450 (ext. 5139),Fax: +1-520-629-4737,E-mail: Ronnie.Fass@va.gov

Conflicts of interest: None. 
be defined as the presence of typical symptoms of gastroesophageal reflux disease caused by intraesophageal reflux (acidic or weakly acidic), in the absence of visible esophageal mucosal injury at endoscopy. ${ }^{1}$

Recently, the Montreal International Consensus defined GERD as a condition that develops when the reflux of stomach contents causes troublesome reflux-associated symptoms, and NERD was defined by the presence of these symptoms in the absence of esophageal mucosal breaks. ${ }^{6}$

Studies have shown that about $30-50 \%$ of NERD patients demonstrate esophageal acid exposure within the physiological range. ${ }^{7}$ The Rome II Committee for Functional Esophageal Disorders considered these patients as having functional heartburn, defined as "episodic retrosternal burning in the absence of pathological gastroesophageal reflux, pathology-based motility disorders, or structural explanations." ${ }^{8}$ This subgroup was further divided into 2 subgroups. The first subgroup included patients who demonstrated a close temporal relationship between their heartburn symptoms and acid reflux events, in spite of having physiological range of esophageal acid exposure. This subgroup accounts for up to $40 \%$ of patients with functional heartburn and has been termed the hypersensitive esophagus. ${ }^{7}$ Patients with hypersensitive esophagus demonstrate partial response to PPI treatment. ${ }^{9}$ In contrast, the other subgroup (up to $60 \%$ ) demonstrates lack of any correlation between heartburn episodes and acid reflux events. The Rome III Committee for
Functional Esophageal Disorders redefined the functional heartburn group, and consequently NERD, by primarily incorporating the hypersensitive esophagus group and those patients with negative symptom association who are responsive to PPI treatment back into the NERD group (Fig. 1). ${ }^{10}$

\section{Epidemiology}

Several early studies reported that about $50 \%$ of patients with heartburn were found to exhibit normal esophageal mucosa during endoscopy. ${ }^{11,12}$ There after, several community-based European studies of NERD patients found a much higher prevalence of up to $70 \%{ }^{13,14}$ Galmiche et al. ${ }^{15}$ assessed the efficacy of on-demand $\mathrm{H}_{2} \mathrm{RA}$ therapy in patients with GERD symptoms who were recruited from general practice clinics. A total of 423 GERD patients were included in this study; and, of those, $71 \%$ met the criteria for NERD. Carlsson et al. ${ }^{16}$ compared different treatment strategies for GERD at 36 primary care centers in Europe and Australia and noted that $49 \%$ of the 538 enrolled patients lacked esophageal mucosal breaks.

In the United States, Robinson et al. ${ }^{17}$ evaluated only subjects who used antacids for symptomatic relief of heartburn. Of 165 patients enrolled in this study, 53\% had normal esophageal mucosa on upper endoscopy. In a recent population-based study, 1,000 subjects with or without GERD-related symptoms from an adult population of 2 Swedish municipalities were randomly se-

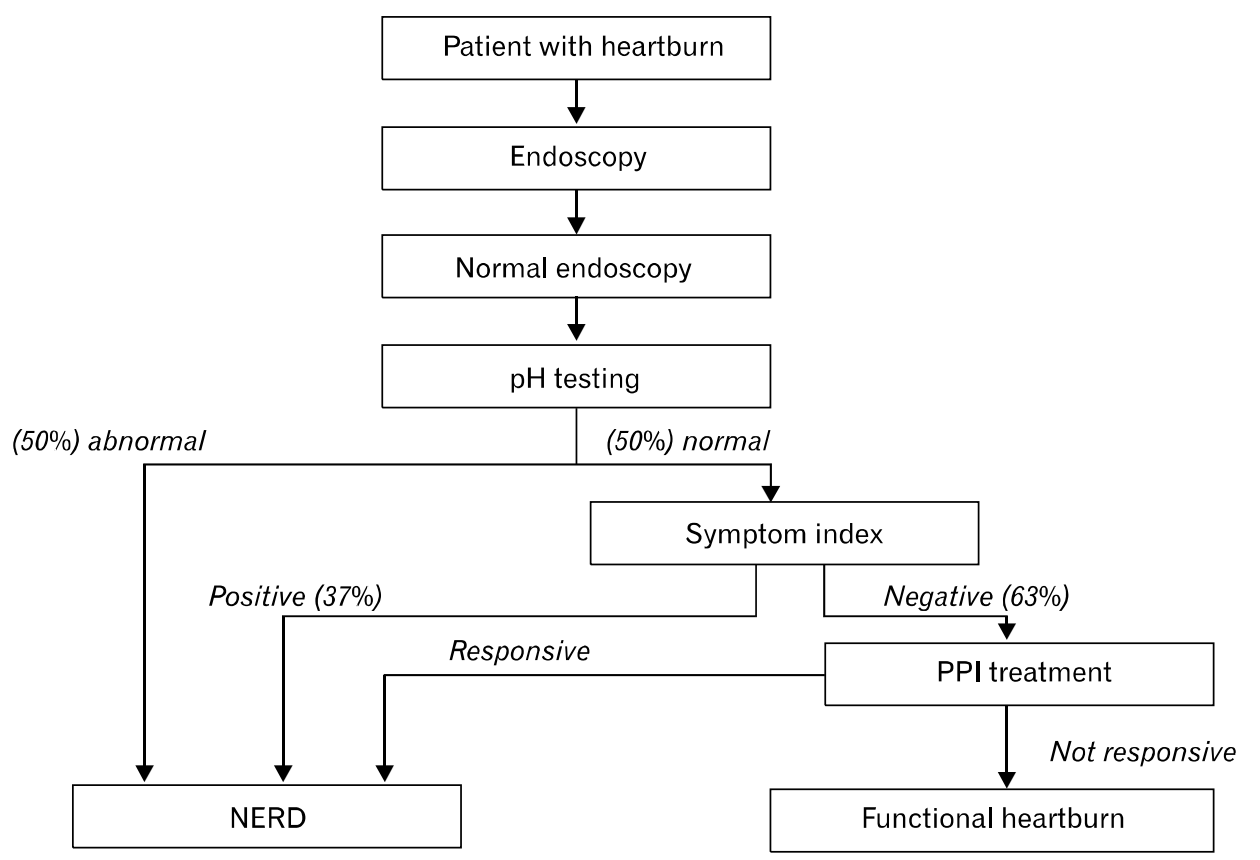

Figure 1. A diagnostic algorithm for NERD and functional heartburn based on Rome III criteria. ${ }^{10}$ 
lected to undergo an upper endoscopy. Of the patients with gastroesophageal reflux symptoms, only $24.5 \%$ were found to have erosive esophagitis. ${ }^{18}$ More recently, Zagari et al. performed a large epidemiologic study in the general population of 2 villages in northern Italy and demonstrated a $23.7 \%$ (out of 1,033 subjects) prevalence rate of patients with reflux symptoms at least twice a week. Of those patients with reflux symptoms, $75.9 \%$ were found to have a negative endoscopy. ${ }^{19}$

Overall, the results of old and recent epidemiologic studies investigating patients with GERD-related symptoms have suggested that the prevalence of NERD in the general population is between $50 \%$ and $70 \%$. Because the usage of proton pump inhibitors (PPIs) has become so widespread, it is likely that some of the recent studies that determined the prevalence of NERD have been contaminated by including healed erosive esophagitis subjects as NERD patients.

\section{Natural History}

Within the spectrum of GERD, the pathophysiological relationship between NERD and erosive esophagitis remains the subject of great debate. ${ }^{20}$ The assumption that NERD and erosive esophagitis represent 1 continuous disorder has been challenged by studies demonstrating differences in relation to epidemiological features, pathophysiological characteristics, and responses to treatment. ${ }^{21-23}$

Pace et al. ${ }^{24}$ performed a retrospective evaluation of patients with NERD. The authors followed 33 patients with NERD and documented abnormal esophageal $\mathrm{pH}$ monitoring for a period of 3-6 months while on therapy with antacids, prokinetics or both. Five (15\%) of the patients that remained symptomatic during therapy developed erosive esophagitis (unknown grading). Pretreatment $\mathrm{pH}$ testing results were not predictable of erosive esophagitis development. In this study, patients were treated from the time of admittance into the study, suggesting that some may have not been true NERD patients. Furthermore, the observation in the study that NERD patients rapidly progressed to develop erosive esophagitis after only a very short duration of follow-up (3-6 months) may further support the conclusion that those who developed erosive esophagitis during the study period were likely healed erosive esophagitis patients that were falsely labeled as having NERD from the beginning.

Kuster et al. ${ }^{25}$ followed 109 patients with GERD, of whom 33 had endoscopically documented erosive esophagitis. The authors used a step-up approach in which patients initially received antacids and prokinetics, and if symptoms continued an $\mathrm{H}_{2} \mathrm{RA}$ was prescribed. Patients that did not respond to an $\mathrm{H}_{2} \mathrm{RA}$ were referred for antireflux surgery. At the 3-year follow-up, 109 patients were available for evaluation, and of those $52 \%$ required only antacids plus prokinetics to control their symptoms. At the 6-year follow-up, 89 patients were available for evaluation, and of those $55 \%$ required only antacids plus prokinetics to control their symptoms. Regardless of therapy, only $2.7 \%$ of the NERD patients developed erosive esophagitis after 3 years and $3 \%$ after 6 years of follow-up. Unlike Pace et al., ${ }^{24}$ this study provided longer duration of follow-up, and despite its limitations very few NERD patients progressed to develop esophageal mucosal injury. Isolauri et al. ${ }^{26}$ conducted a longer duration follow-up (17-22 years, mean 19.5 years) of 60 patients with documented GERD. Patients received medical (50) or surgical (10) antireflux therapy as needed (no standardization). Of the 50 subjects that received only medical therapy, 30 had NERD and 20 erosive esophagitis at baseline. At follow-up, only 5 (17\%) of the NERD patients progressed to develop erosive esophagitis (all to grade 1 Savary-Miller).

McDougall et al. ${ }^{27}$ conducted a 10 year follow-up of $152 \mathrm{pa}-$ tients with typical GERD symptoms and grade 1-3 erosive esophagitis (modified Savary-Miller) documented during an upper endoscopy. Over $70 \%$ of the patients still had heartburn daily or at least weekly at follow-up. Patients reporting dysphagia underwent repeat endoscopy, revealing 2 new benign peptic strictures and 1 Barrett's esophagus. However, because this was a survey study and patients were allowed to be on and off treatment ad libitum, it is difficult to interpret the findings. Furthermore, the presence of so-called "new Barrett's esophagus" may well be an unrecognized Barrett's mucosa that was present underneath esophageal inflammation. In another study, McDougall et al. ${ }^{28}$ performed a prospective follow-up of 101 GERD patients for a period of at least 32 months after initial assessment with $\mathrm{pH}$ testing and an upper endoscopy. During follow-up, more than half of the patients were on a PPI or $\mathrm{H}_{2} \mathrm{RA}$. Of the 17 subjects with NERD and abnormal pH testing, 4 (24\%) developed erosive esophagitis while on $\mathrm{H}_{2} \mathrm{RA}$. Again, the authors' report in this study that 3 patients with erosive esophagitis developed Barrett's esophagus may also represent an unrecognized Barrett's mucosa that was present underneath the esophageal inflammation.

Manabe et al. ${ }^{29}$ followed 105 patients with mild erosive esophagitis (Los Angeles classification A and B) for a mean duration of 5.5 years. Only $10.5 \%$ of the patients progressed to higher grading (mostly Los Angeles grade $\mathrm{C}$ ), and none have pro- 
Table 1. The Largest Population-based Studies Assessing Progression of NERD to Erosive Espophagitis ${ }^{23}$

\begin{tabular}{lrrc}
\hline \multicolumn{1}{c}{ Study } & $\mathrm{N}$ & Follow-up & Progression \\
\hline Labenz $^{32}$ & 3,894 & 2 years & $25.5 \%$ \\
Sontag $^{35}$ & 2,306 & 7.6 years & $0 \%$ \\
Bardhan $^{36}$ & 12,374 & 24 years & $4.4 \%$ \\
\hline
\end{tabular}

gressed to Barrett's esophagus. This study suggests that even within the different gradings of erosive esophagitis, there is very little progression over time.

Two recent retrospective studies stand out in their findings about the natural course of GERD. Unlike the aforementioned studies as well as other more recently published articles (vide infra), Pace et al. ${ }^{30}$ have reported a $94 \%$ progression of NERD to erosive esophagitis. Using their original cohort of GERD subjects, ${ }^{24}$ the authors were able to endoscope 18 of 33 subjects. Seventeen (94\%) were found to have esophageal mucosal inflammation (erosive esophagitis). The authors concluded that GERD is a chronic disease characterized by increasing severity in time, requiring protracted medical therapy. Although the authors provide only 2 endoscopies (index and follow-up), they concluded that almost all NERD patients are destined to progress over time to develop erosive esophagitis, regardless of the extent of their esophageal acid exposure. ${ }^{31}$ The study does not provide evidence of increased severity in gastroesophageal reflux that parallels the new endoscopic findings. In contrast to the previous study, Labenz et al. have recently proposed a highly complex model to describe the natural course of GERD. ${ }^{32}$ Using the ProGERD (progression of gastroesophageal reflux disease) database, the authors evaluated progression or regression in GERD. Interestingly, the study demonstrated significant progression and regression after 2 years of follow-up. ${ }^{31}$ The authors showed that $24.9 \%$ of the NERD patients progressed to develop low-grade erosive esophagitis (Los Angeles classification grades $\mathrm{A}$ and $\mathrm{B}$ ), and $0.6 \%$ developed severe erosive esophagitis (Los Angeles classification grades C and D). Surprisingly, 50.4\% of those with grades $\mathrm{C}$ and $\mathrm{D}$ and $61.3 \%$ with grades $\mathrm{A}$ and $\mathrm{B}$ regressed to NERD. Again, the study provides only 2 endoscopies (index and follow-up), and thus the durability of the described esophageal mucosal findings is unknown. Furthermore, $73 \%$ of the subjects in this study had taken antireflux medications, and $61 \%$ had visited a physician. ${ }^{33}$ The study suggests for the first time that patients move freely and in large numbers from NERD to erosive esophagitis and back again.

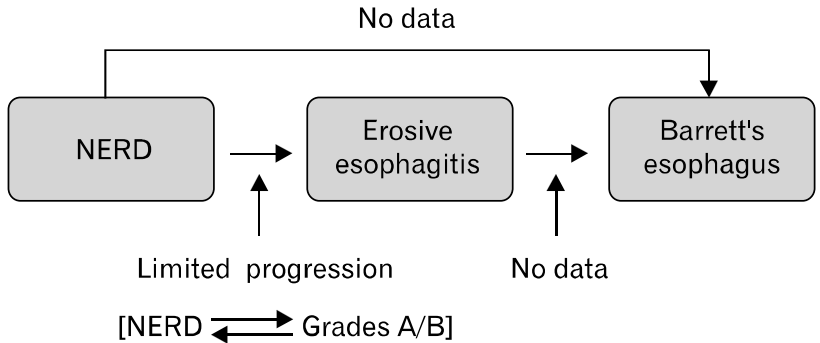

Figure 2. Proposed new paradigm for the natural course of NERD. ${ }^{23}$

Garrido Serrano et al. followed 692 GERD patients over a period of 6 years and prospectively assessed progression or regression along the spectrum. ${ }^{34}$ The authors found that patients with NERD (50\% of the sample) did not develop erosive esophagitis and those with erosive esophagitis remained within the stage of the initial diagnosis. Sontag et al. ${ }^{35}$ evaluated 4,633 patients undergoing endoscopy for reflux symptoms over a mean follow-up period of 7.6 years. The patients received antireflux medications, but treatment regimens were not standardized for all patients. The authors were unable to document progression of NERD along the spectrum. Bardhan et al. provided the longest and largest natural history data evaluating 12,374 GERD patients over a period of 24 years. ${ }^{36}$ The authors were able to document only $4.4 \%$ progression to erosive esophagitis among the NERD patients.

Overall, the currently available natural course studies suggest that lack of progression is more common than progression along the spectrum for patients with NERD (Table 1). Most importantly, there is no evidence that NERD patients may progress over time to develop Barrett's esophagus.

Fass and Ofman ${ }^{22}$ proposed a novel paradigm suggesting that GERD patients exhibit 3 phenotypic presentations: NERD erosive esophagitis, and Barrett's esophagus. The vast majority of NERD and erosive esophagitis patients remain within their respective GERD groups throughout their lifetime. This new paradigm proposes that the genetic makeup of each individual subject exposed to similar environmental factors may ultimately determine the specific phenotypic presentation of GERD (Fig. $2)^{22,23}$ In other words, GERD phenotypes once determined remain true to form. ${ }^{35,37}$

\section{Pathophysiology}

Current concepts in the pathophysiology of NERD involve 
peripheral factors (luminal, mucosal, and sensory afferents) as well as central (psychological, stress, sleep, etc.).

Overall, there is no difference in gastric acid output between NERD patients and those with erosive esophagitis. ${ }^{38}$ The level of esophageal acid exposure in NERD patients has been examined by Martinez et al. ${ }^{39}$ The authors demonstrated that only $45.1 \%$ of NERD patients had an abnormal $\mathrm{pH}$ test compared with $75 \%$ of patients with erosive esophagitis and $92.9 \%$ of patients with Barrett's esophagus. The mean recorded number of acid reflux events was 95.3 in NERD versus 139.7 in those with erosive esophagitis. Furthermore, patients with NERD had the lowest esophageal acid exposure profile $(\mathrm{pH}<4)$ in \% total, recumbent, and upright time as compared to the other GERD groups. In fact, the mean esophageal acid exposure values were only mildly abnormal. ${ }^{40}$ Unlike patients with erosive esophagitis and Barrett's esophagus who demonstrate intense acid exposure in the very distal portion of the esophagus, NERD patients have very little variation in esophageal acid exposure distribution throughout the esophagus (total and recumbent). ${ }^{41}$ Shapiro et al. have shown a marked overlap in acid exposure between NERD patients and those with erosive esophagitis and even those with Barrett's esophagus (Table 2). ${ }^{40}$ This study suggests that other environmental and genetic factors play an important role in disease presentation.

Adachi et al. have demonstrated that NERD patients had significantly lower nighttime esophageal acid exposure as compared to patients with grade C and D erosive esophagitis. ${ }^{42}$ Dickman et al. have demonstrated that the esophageal acid exposure pattern during sleep is similar among the different GERD groups. ${ }^{43}$ NERD patients with abnormal $\mathrm{pH}$ test had similar level of esophageal acid exposure during sleep as patients with erosive esophagitis. Esophageal acid exposure was the highest at the beginning of sleep and markedly dropped toward the middle of the sleep period.

Several luminal factors were found to be predictors of a

Table 2. The Extent of the Overlap of Esophageal Acid Exposure (time $\mathrm{pH}<4$ ) among the Different GERD Groups ${ }^{40}$

\begin{tabular}{cccc}
\hline $\begin{array}{c}\text { Group } \\
\text { compared }\end{array}$ & $\begin{array}{c}\text { Total } \\
(\%)\end{array}$ & $\begin{array}{c}\text { Upright } \\
(\%)\end{array}$ & $\begin{array}{c}\text { Recumbent } \\
(\%)\end{array}$ \\
\hline BE, EE & 47.8 & 40.7 & 24 \\
BE, NERD & 31.6 & 37.5 & 20.8 \\
EE, NERD & 47.4 & 64.7 & 81.8 \\
\hline
\end{tabular}

$\mathrm{BE}$, Barrett's esophagus; EE, erosive esophagitis. sensed acid reflux event as compared to a non-sensed acid reflux event (using impedance $+\mathrm{pH}$ sensor), and they include proximal migration of an acid reflux event, larger $\mathrm{pH}$ drops, lower $\mathrm{pH}$ nadir, larger volume and acid clearance time, preceding higher esophageal cumulative acid exposure time, and presence of gas in the refluxate. ${ }^{44,45}$ Recently, Schey et al. have shown that NERD patients demonstrated the highest number of acid reflux events before sensed reflux event as compared with other heartburn groups. This suggests that prior sensitization is needed for an acid reflux to be perceived in NERD patients who demonstrated a lower acid exposure compared with erosive esophagitis patients. ${ }^{46}$ Proximal esophageal migration of a reflux event has been shown to be an important predictor of symptom generation in NERD patients as well as other GERD groups, regardless if the reflux is acidic or weakly acidic. ${ }^{47}$ The underlying mechanism for this phenomenon is unknown. Some have stipulated that it is likely due to summation effect (the higher the reflux, the more esophageal pain receptors are sensitized) or increased sensitivity of the proximal portion of the esophagus to either chemical or mechanical stimuli.

The role of nonacid reflux in NERD was recently assessed by esophageal impedance-pH monitoring in 150 NERD patients. NERD patients had more reflux episodes (acid and nonacid) as compared to controls. A total of $42 \%$ of patients had abnormal esophageal acid exposure as compared to controls. In the subgroup of patients with normal acid exposure, $15 \%$ had positive symptom-association probability (SAP) for acid, $12 \%$ for nonacid reflux, and $5 \%$ for both. ${ }^{48} \mathrm{~A}$ recent study conducted in a small group of normal subjects has demonstrated that acidic or weakly acidic solutions can result in the development of dilated intercellular spaces (DIS). ${ }^{49}$ That suggests that NERD patients are likely to develop similar mucosal abnormalities from both types of gastroesophageal reflux.

There are very limited data concerning the role of bile reflux in symptom generation of patients with NERD. The mean fasting gastric bile acid concentration in NERD patients is similar to healthy controls. Additionally, combined acid and duodenogastroesophageal reflux, which correlates with severity of mucosal involvement in GERD, has been documented in only $50 \%$ of NERD patients compared with $79 \%$ of erosive esophagitis patients. $^{50}$

Physiological studies in patients with NERD have revealed minimal esophageal abnormalities. These patients have a slightly higher rate of primary peristalsis failure, defined by non-transmitted contractions or peristaltic contractions that do not traverse 
the entire esophageal body as compared to normal controls. ${ }^{51}$ Recently, it has been demonstrated that the rate of triggering secondary peristalsis in patients with NERD was significantly lower than in normal controls. However, when secondary peristalsis did occur in NERD patients, there was no difference in amplitude and velocity when compared to normal controls. ${ }^{51}$ However, the abnormality in secondary peristalsis may explain the overall homogeneous distribution of acid reflux that was observed by Dickman et al. ${ }^{41}$ Distal amplitude contractions, as well as mean lower esophageal resting pressure, are mildly reduced in NERD patients as compared with normal subjects. Resting lower esophageal sphincter pressure is rarely below $10 \mathrm{mmHg} .{ }^{20}$ In contrast, $25 \%$ of patients with mild erosive esophagitis and $48 \%$ of those with severe erosive esophagitis demonstrate peristaltic dysfunction. The mean resting lower esophageal sphincter pressure is significantly lower in patients with erosive esophagitis as compared to those with NERD. ${ }^{20,38}$

Hiatal hernia occurs in only the minority of NERD patients. Cameron et al. ${ }^{52}$ compared hiatal hernia rates in patients with NERD versus those with erosive esophagitis and demonstrated that $29 \%$ of the NERD patients had hiatal hernia as compared with $71 \%$ of those with erosive esophagitis. The absence of diaphragmatic hernia suggests that transient lower esophageal sphincter relaxation is likely the predominant mechanism for gastroesophageal reflux in most of the NERD patients. ${ }^{53}$

In most NERD patients, DIS (with a cut-off values of more than $0.56 \mathrm{~nm}$ ) could be identified using electron micrograph. ${ }^{54}$ The occurrence of DIS in NERD is attributed to esophageal mucosal exposure to gastroesophageal reflux and possibly even other stimuli. ${ }^{3}$ Mastracci et al. have demonstrated that Ki 67 nuclear antigen, which is expressed by proliferating cells and provides an objective way to measure the regeneration of squamous epithelium, can serve as a marker that can distinguish NERD patients from normal controls. ${ }^{55}$

Visceral hypersensitivity has been considered to be an important pathophysiological mechanism in NERD. Three broad mechanisms are believed to underlie visceral hypersensitivity: peripheral sensitization, central sensitization, and psychoneuroimmune interactions. ${ }^{56}$

In general, assessment of esophageal sensitivity in NERD patients has yielded evidence for reduced perception thresholds for painful stimuli. However, results are difficult to compare due to different sensory testing protocols as well as stimuli. Furthermore, many studies evaluate so-called "NERD patients" without excluding the functional heartburn group.
Miwa and colleagues have specifically evaluated stimulus response functions to acid in patients with NERD, as compared to other GERD groups, using an acid perfusion paradigm. ${ }^{57}$ The authors demonstrated that NERD patients had lower perception thresholds for pain, especially as compared to normal controls, but also as compared to those with erosive esophagitis and Barrett's esophagus. In a subsequent study, the authors confirmed their previous results but also noted that NERD patients were more sensitive to saline than subjects with erosive esophagitis. ${ }^{58}$ The authors concluded from this study that NERD patients display a more general esophageal hypersensitivity that is not limited to acidic stimuli only. Even when compared to functional heartburn, NERD patients with abnormal $\mathrm{pH}$ testing demonstrated lower perception thresholds for pain using a similar acid perfusion paradigm. ${ }^{59}$ It has been proposed that the functional heartburn group, as compared to NERD patients, is a heterogeneous group composed of those with esophageal hypersensitivity to acid and others who show no sensitivity to any chemical stimuli. An interesting study has demonstrated that the proximal esophagus in NERD patients is more sensitive to acid perfusion as compared to the distal esophagus. ${ }^{60}$ The study may provide 1 of the explanations for the strong relationship between proximal esophageal migration of acid reflux and symptoms generation in GERD patients.

Mechanical and thermal stimulation of the esophagus were also assessed in NERD patients. In a study by Reddy et al., the authors used a multimodal stimulation probe to assess pain evoked by either thermal or mechanical stimuli. ${ }^{61}$ NERD patients demonstrated increased esophageal sensitivity only to heat stimuli but not to cold or mechanical stimuli as compared to normal controls. However, other studies have also demonstrated an increased sensitivity to mechanical stimuli (balloon distention) in NERD patients as compared to the other GERD groups. ${ }^{62}$

Several receptors have been identified as mediating esophageal hypersensitivity due to acid including up-regulation of acid sensing ion channels, increased expression of TRPV1 receptors (transient receptor potential vanilloid type 1), and prostaglandin E-2 receptor (EP-1). ${ }^{63,64}$

Various central mechanisms have also been shown to influence processing of afferent signals at the brain level. ${ }^{65}$ Psychological stresses and emotional perturbation have been demonstrated to potentiate perception of intraesophageal stimuli. By using dichotomous listening, Fass et al. demonstrated that acute laboratory stress increased sensitivity to intraesophageal acid perception in patients with either erosive or nonerosive reflux 


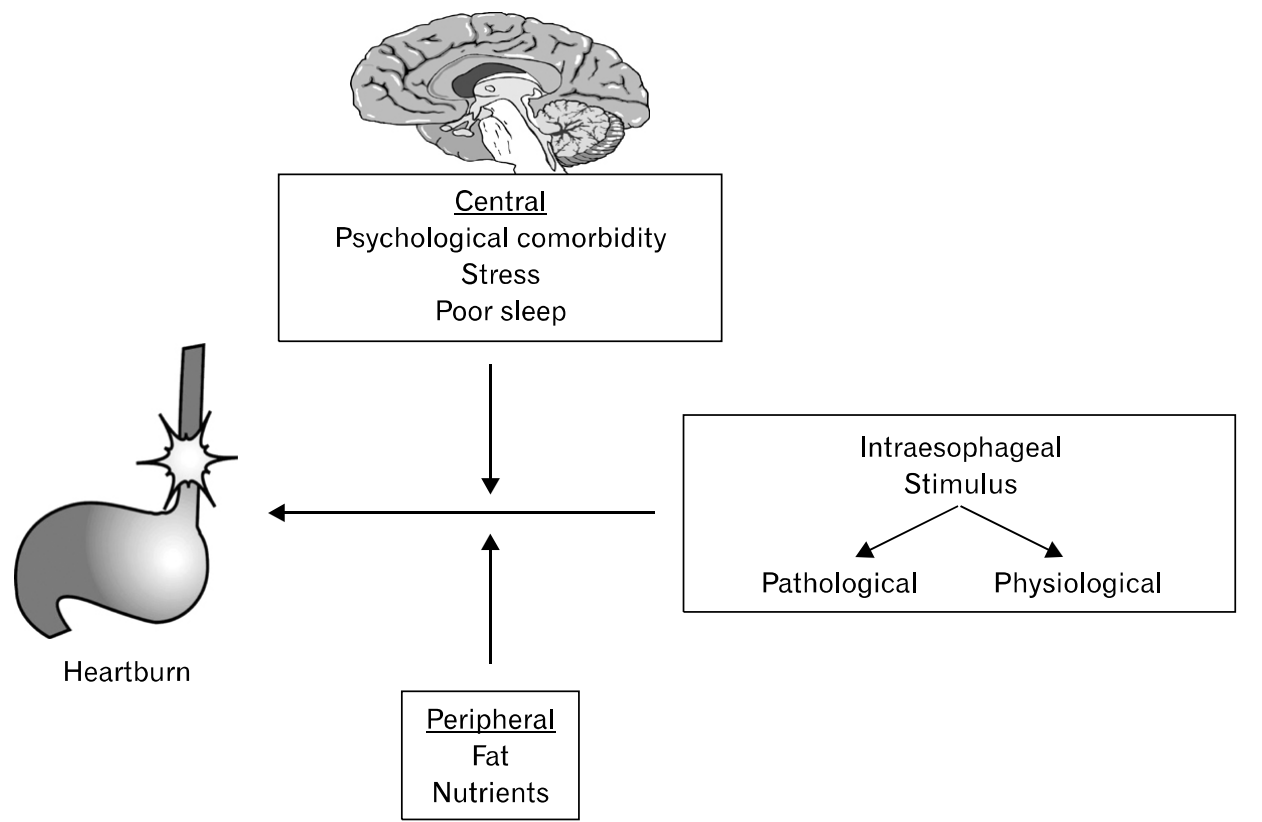

Figure 3. The "Fass and Tougas" conceptual model for esophageal symptom generation in NERD. ${ }^{68}$

disease. ${ }^{66}$ The authors also noted that the increase in perceptual responses to acid was associated with greater emotional response to the stressor. Sleep deprivation has also been shown to induce esophageal hypersensivity to acid perfusion, although the study was carried out only in patients with erosive esophagitis. ${ }^{67}$

\section{Models for Heartburn in NERD}

Several models for heartburn in NERD patients have been proposed. Fass and Tougas suggested that intraesophageal stimuli, either pathologic or physiologic, may lead to symptoms in NERD patients. In their model, the authors emphasized the role of central (through brain-gut interactions) and peripheral (not esophageal) mechanisms in modulating perception of intraesophageal stimuli (Fig. 3). ${ }^{68}$

Barlow and Orlando proposed the following model to explain the pathophysiology of NERD: DIS enables the diffusion of refluxed gastric acid into the intercellular spaces. Then, acid reach-

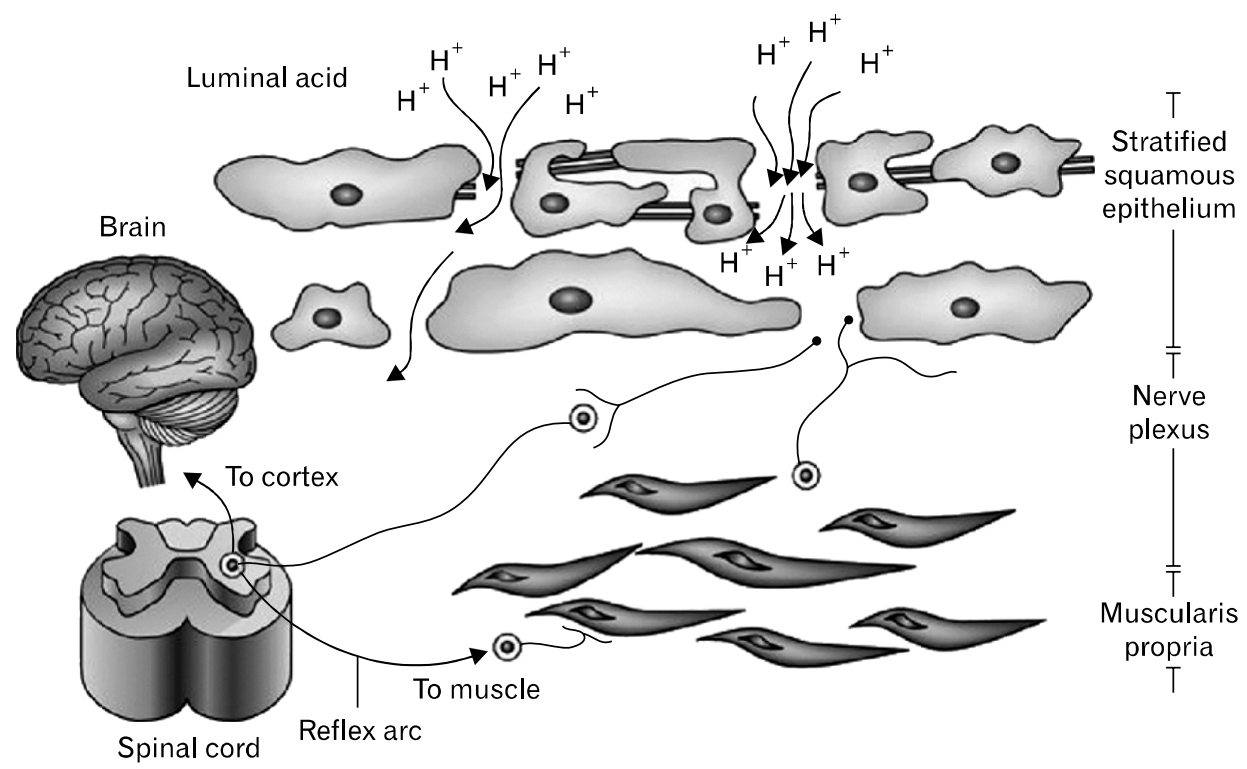

Figure 4. The "Barlow and Orlando" suggested model for heartburn in patients with NERD. ${ }^{69}$ 


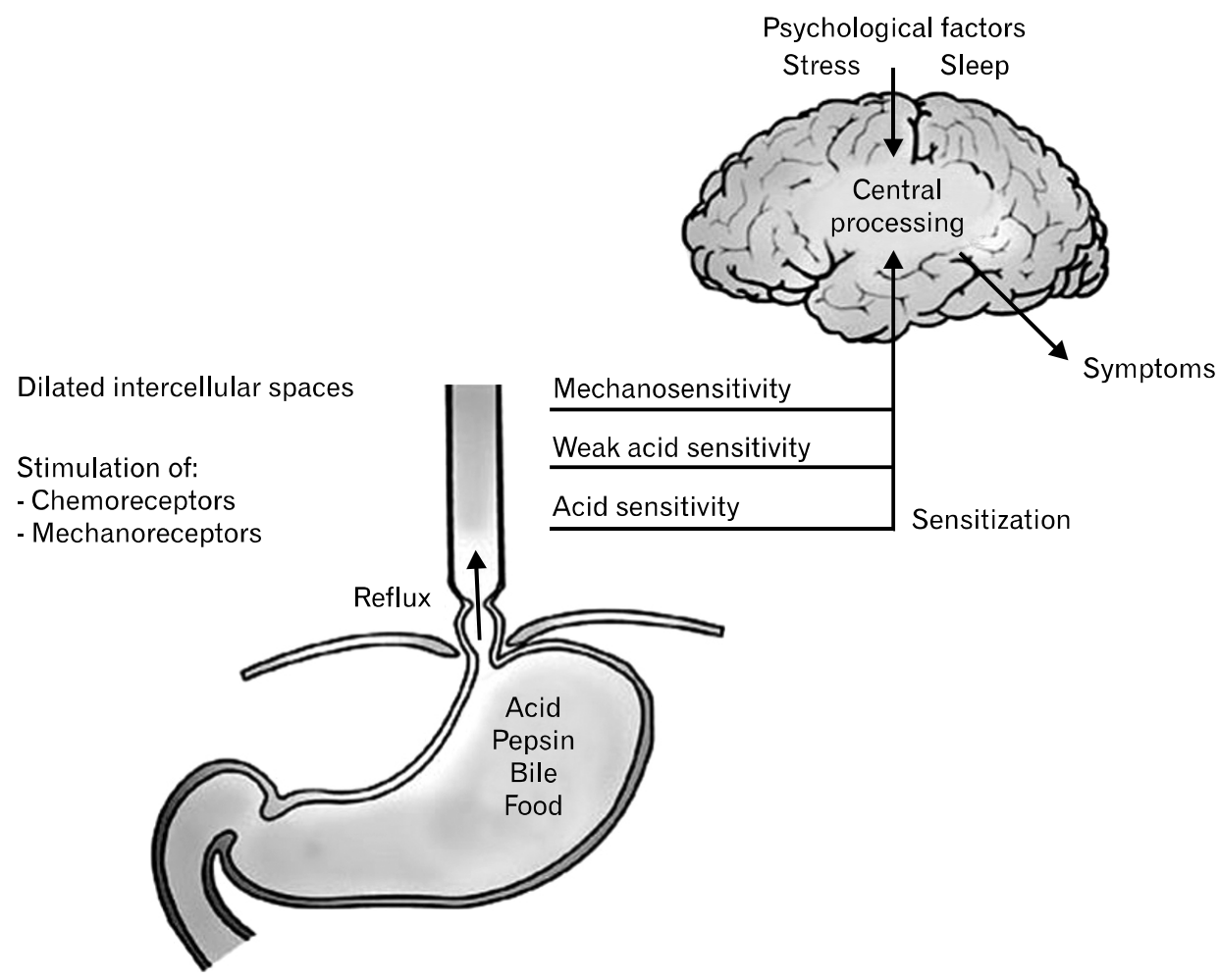

Figure 5. The "Ang, Sifrim and Tack" model for heartburn in NERD. ${ }^{70}$

es and activates chemosensitive nociceptors whose signals are transmitted via the dorsal horn of the spinal cord to the brain for symptoms perceptions (Fig. 4). ${ }^{69}$

The "Ang, Sifrim and Tack" model combines many of the concepts put forth by the 2 previously mentioned conceptual models (Fig. 5). ${ }^{70}$ This model emphasizes the value of esophageal hypersensitivity to both mechanical and chemical stimuli.

\section{Clinical Characteristics}

A large study involving 25 centers in Denmark and Sweden reported on 424 patients with troublesome heartburn associated with NERD. The mean age of the population was $50 \mathrm{yr} ; 58 \%$ were female; only $21 \%$ were smokers; $45 \%$ were active alcohol users; $53 \%$ had more than a 5 -year history of heartburn; and only $37 \%$ had hiatal hernia documented during upper endoscopy. ${ }^{71}$ Carlsson et al. ${ }^{16}$ compared the clinical characteristics of patients with NERD and those with erosive esophagitis. In the NERD group, $60 \%$ were female; the mean age was $49 \mathrm{yr}$; mean weight was $80.5 \mathrm{~kg}$ for males and $69.5 \mathrm{~kg}$ for females; $23 \%$ were smokers; $59 \%$ were alcohol consumers; $80 \%$ had symptom duration longer than 12 months; $29 \%$ had hiatal hernia; and 34\% were positive for Helicobacter pylori. The erosive esophagitis group was similar to the NERD group in mean age, smoking and alcohol consumption, prevalence and duration of heartburn, and status of Helicobacter pylori infection. However, there were more males $(59 \%)$ in the erosive esophagitis group, increased prevalence of hiatal hernia $(56 \%)$, and increased weight of both males and females ( $86 \mathrm{~kg}$ and $76 \mathrm{~kg}$, respectively).

Increase in body mass index (BMI) is associated with increased risk for having erosive esophagitis. ${ }^{72}$ Furthermore, obese patients (BMI $\geq 30 \mathrm{~kg} / \mathrm{m}^{2}$ ) demonstrate a higher prevalence of erosive esophagitis $(26.5 \%)$ as compared to normal-weight subjects $(9.3 \%){ }^{73}$ The effect of metabolic risk factors on the natural history of GERD was quantified in a large population undergoing repeated endoscopy. Being male, smoking, or having metabolic syndrome independently increased the likelihood of progression from NERD to erosive esophagitis. ${ }^{74}$

Psychological comorbidities in GERD patients have been shown to predict the presence of GERD-related symptoms regardless of the presence or absence of esophageal mucosal injury. ${ }^{75-77}$ Patients with higher emotional sensitivity or neuroticism complain more frequently of GERD symptoms such as heartburn. However, studies did not find a specific correlation between psychological comorbidity and esophageal mucosal damage or extent of esophageal acid exposure. ${ }^{78}$ 
A recent study by Wu et al. ${ }^{79}$ evaluated the clinical characteristics of patients with NERD in comparison to those with erosive esophagitis. Each patient underwent endoscopy, esophageal manometry, acid perfusion test, and ambulatory 24-hour esophageal $\mathrm{pH}$ monitoring. The authors found that NERD patients had a significantly higher prevalence of functional bowel disorders such as functional dyspepsia and irritable bowel syndrome, psychological disorders, and positive acid perfusion test. Patients with erosive esophagitis were characterized by higher prevalence of hiatal hernia, greater esophageal acid exposure, and more esophageal dysmotility.

Irritable bowel syndrome (IBS) like symptoms as well as dyspepsia-like symptoms are very commonly reported by NERD patients. ${ }^{79,80}$ However, the association with functional bowel symptoms is not distinctive to NERD and is also very common in erosive esophagitis patients. These symptoms were demonstrated to independently determine reflux symptoms severity in NERD patients as compared to normal controls. ${ }^{81}$ In a study comparing NERD and functional heartburn patients, bowel symptoms were similarly scored by both groups, but the severity of reflux symptoms was independently associated with the bowel symptoms. ${ }^{82}$

Clinical studies have demonstrated that heartburn severity and intensity are similar in patients with erosive esophagitis and those with NERD. ${ }^{83}$ Additionally, the impact of heartburn severity on patients' quality of life was similar in both GERD groups as well. ${ }^{16,84}$ Furthermore, sleep dysfunction is similar between patients with NERD and those with erosive esophagitis. ${ }^{85}$

\section{Diagnosis}

Upper endoscopy is the most sensitive diagnostic tool for assessing GERD-related esophageal mucosal injury such as erosions, ulceration, stricture, Barrett's esophagus, and others. However, uncertainty in detecting mucosal breaks and in describing their severity can lead to inconsistency among different endoscopists. This is particularly essential in diagnosing NERD because of the need to demonstrate normal endoscopic examination of the esophageal mucosa. However, several recent studies using high resolution magnification endoscopy demonstrated the presence of minimal mucosal changes at the squamocolumnar junction of GERD patients with normal conventional upper endoscopy. The changes included vascular injection or vascular spots above the Z-line, villous mucosal surface, mucosal islands, and microerosions. ${ }^{86}$ Others have added Lugol chromoendoscopy to further evaluate NERD patients for minimal esophageal changes at the squamocolumnar junction. Visible unstained streaks by Lugol chromoendoscopy were considered indicative of mucosal injury (as was further substantiated by biopsy). ${ }^{87}$

Recently, narrow-band imaging (NBI) was introduced for better visualization of mucosal and microvascular patterns at the esophagogastric junction of NERD patients with normal endoscopy. This technique utilizes spectral narrow band filters and enables imaging of superficial tissue structures such as capillary and mucosal patterns without the use of dye. Sharma et al. demonstrated that the presence of microerosions and increased vascularity at the squamocolumnar junction were the best predictors for GERD diagnosis. These results were further confirmed when subgroup analysis of NERD and erosive esophagitis was compared separately to controls. Although the interobserver agreement for various NBI findings was very good, the intraobserver agreement was modest. ${ }^{88} \mathrm{~A}$ subsequent study demonstrated that the intra-and interobserver reproducibility in grading esophageal mucosal changes could be improved when NBI was applied together with conventional imaging. This additional benefit appeared to derive from better depiction of small erosions. ${ }^{89}$

As a result of the aforementioned and other studies, the term "minimal change esophagitis" was introduced, and further studies claimed that these mucosal changes can be detected in many patients with NERD. ${ }^{90}$ Consequently, some authors went further and proposed that NERD patients with normal conventional endoscopy, but with minimal changes at the squamocolumnar junction during magnification endoscopy, chromoendoscopy or NBI, should be considered as having erosive esophagitis. However, there were no attempts to correlate minimal mucosal changes with esophageal physiological abnormalities and to show that these patients are truly closer to erosive esophagitis than to NERD. In addition, the clinical implications of these findings remain to be elucidated. One study has already demonstrated that patients with the so-called "minimal change esophagitis" have different physiological characteristics than patients with erosive esophagitis. ${ }^{90}$ Furthermore, concerns have been raised about the inter-and intraobserver variability of these minute lesions. Thus, the value of documenting minimal mucosal changes in NERD patients is presently unclear. Furthermore, the yield of identifying these lesions should be weighed against the cost of the needed equipment and the availability of more economical strategies to handle these patients.

Distinguishing NERD patients from those with eosinophilic esophagitis has become a major area of interest in the past few years. Whilst most of those with classic GERD symptoms are un- 
likely to have eosinophilic esophagitis, it is those who appear to have some of the clinical and anatomic features of eosinophilic esophagitis who have been the focus of investigation if GERD is the direct underlying cause. ${ }^{91}$ Recently, Dellon et al. compared clinical, endoscopic, and histologic findings between eosinophilic esophagitis and GERD. ${ }^{92}$ Unconditional logistic regression was performed to develop a model to predict eosinophilic esophagitis, and receiver operator characteristic curves were constructed. The authors found that, as compared with GERD, features that independently predict eosinophilic esophagitis included younger age, dysphagia, food allergy, esophageal rings, linear furrows, white plaques or exudate, absence of hiatal hernia, a higher maximum eosinophil count, and the presence of eosinophil degranulation in the biopsy specimen. The area under the curve for this model was 0.934 .

Ambulatory 24-hour esophageal $\mathrm{pH}$ monitoring is essential for diagnosing NERD, especially after the recent introduction of the new definitions for functional heartburn by the Rome III Committee for Functional Esophageal Disorders. ${ }^{10}$ However, the test is not commonly done in practice, and response to PPI treatment has been used instead to identify the functional heartburn patients. ${ }^{93-95}$ Esophageal impedance $+\mathrm{pH}$ has been used extensively to primarily study patients who failed PPI treatment. By using this technique, patients who are not responsive to PPI treatment (up to twice daily) have more than a $50 \%$ chance of having functional heartburn. ${ }^{96}$ However, the role of impedance $+\mathrm{pH}$ in nontreated GERD patients, and more specifically in those with NERD, is likely to be very limited. ${ }^{3}$

\section{Treatment}

PPIs are currently considered the most effective and safe therapeutic modality for GERD. In clinical trials, these agents have consistently been demonstrated to be more effective than any other acid-suppressant agent in healing erosive esophagitis and relieving GERD-related symptoms. The superior efficacy of PPIs is also observed in NERD patients. In a recent meta-analysis, van Pinxteren et al. demonstrated that the relative risk (RR) for heartburn remission in placebo-controlled trials of patients with NERD was 0.68 (95\% CI: 0.59-0.78) for PPIs versus placebo and 0.84 (95\% CI: 0.74-0.95) for $\mathrm{H}_{2} \mathrm{RA}$ versus placebo. ${ }^{97}$ The relative risk for PPIs versus $\mathrm{H}_{2} \mathrm{RAs}$ was 0.74 (95\% CI: 0.53-1.03).

A number of studies evaluated the efficacy of PPIs in NERD patients. In a multicenter, randomized, double-blind study, omeprazole $20 \mathrm{mg}$ once daily was compared with placebo in controlling symptoms of 209 patients with NERD. ${ }^{98}$ After 4 weeks of therapy, $57 \%$ of patients in the omeprazole group were free of heartburn, $75 \%$ were free of acid regurgitation, and $43 \%$ were completely asymptomatic. In another study, NERD patients were randomized to omeprazole $20 \mathrm{mg}$ /day, omeprazole 10 $\mathrm{mg} /$ day, or placebo. ${ }^{13}$ The study authors found that at 4 weeks, $46 \%$ of patients treated with omeprazole $20 \mathrm{mg} /$ day, $31 \%$ treated with omeprazole $10 \mathrm{mg} /$ day, and $13 \%$ of those who received placebo reported complete relief of heartburn. Miner et al. enrolled 203 patients with NERD who were randomized to either rabeprazole $20 \mathrm{mg}$ once daily or placebo. After 4 weeks, $56.7 \%$ of the patients receiving rabeprazole reported satisfactory symptom relief when compared with $32.2 \%$ of those receiving placebo $(\mathrm{p}<$ 0.008). ${ }^{99}$ A recent study that utilized the wireless $\mathrm{pH}$ capsule has demonstrated that PPIs can normalize esophageal acid exposure in patients with NERD within 48 hours after initial administration. $^{100}$

In general, the proportion of NERD patients responding to a standard dose of PPI is approximately 20-30\% lower than what has been documented in patients with erosive esophagitis. In a systematic review of the literature, PPI symptomatic response pooled rate was $36.7 \%$ (95\% CI: 34.1-39.3) in NERD patients and $55.5 \%(95 \% \mathrm{CI}: 51.5-59.5)$ in those with erosive esophagitis. ${ }^{101}$ Therapeutic gain was $27.5 \%$ in NERD as compared with $48.9 \%$ in erosive esophagitis. Moreover, patients with NERD demonstrate a close relationship between response to PPI therapy and degree of esophageal acid exposure. The greater the distal esophageal acid exposure, the higher the proportion of NERD patients reporting symptom resolution. ${ }^{13}$ This is the opposite of what has been observed in patients with erosive esophagitis, where increased esophageal inflammation has been associated with lower response rate to PPI once daily. Patients with NERD also demonstrate longer lag time to sustained symptom response when compared to patients with erosive esophagitis (2 to 3-fold). Furthermore, patients with NERD demonstrate similar symptomatic response to half and full standard dose of PPI, ${ }^{102}$ unlike patients with erosive esophagitis who demonstrate an incremental increase in healing and symptom resolution. In 1 study, the time to first and sustained relief of reflux symptoms during PPI treatment was assessed by the ReQuest ${ }^{\mathrm{TM}}$ questionnaire in NERD patients. Both pantoprazole (20 mg/day) and esomeprazole ( $20 \mathrm{mg} /$ day) have been shown to provide a similar median time to first symptom relief (2 days) and to sustained symptom relief (10-13 days). ${ }^{103}$ The reason for the differences in 
therapeutic response parameters between NERD and erosive esophagitis is primarily due to the common inclusion of functional heartburn subjects in the NERD group. However, because most NERD patients demonstrate only modest abnormal esophageal acid exposure, even after excluding functional heartburn patients, the symptomatic response rate of NERD patients to PPI remains lower that what has been observed in erosive esophagitis patients.

Because GERD is mostly not a progressive disorder, treatment for many of these patients could be symptom driven. Thus, on-demand or intermittent therapy with a PPI is an attractive therapeutic strategy for NERD patients in clinical practice. ${ }^{104,105}$ These therapeutic approaches are convenient, allow patients to remain in control, cost effective, and decrease the likelihood of rebound of acid secretion. Studies have demonstrated that intermittent or on-demand PPI therapy in NERD is effective and associated with improved quality of life as well as reduced cost. ${ }^{106,107}$

Dexlansoprazole MR is a novel, modified-release formulation of dexlansoprazole, which incorporates dual delayed-release technology designed to prolong the serum concentration-time profile, and thus provides extended acid-suppression, has been recently assessed in NERD patients. Dexlansoprazole $30 \mathrm{mg} /$ day for 4 weeks was shown to be superior to placebo in providing 24-hour heartburn-free days and nights ( $54.9 \%$ vs. $17.5 \%$ and $80.8 \%$ vs. $51.7 \%$, respectively). ${ }^{108}$

Novel therapeutic modalities are currently under consideration for GERD patients and specifically those with NERD. The main areas of interest include improving acid suppression, reducing the transient lower esophageal sphincter relaxation rate, decreasing esophageal sensitivity, and enhancing esophageal motility.

Response to antireflux surgery has been shown to be different between patients with NERD versus those with erosive esophagitis. Fenton et al. compared the clinical outcome of anti-reflux surgery in patients with erosive esophagitis versus those with NERD, demonstrating that $91 \%$ versus $56 \%$ reported heartburn resolution, $24 \%$ versus 50\% reported dysphagia post-surgery and $94 \%$ versus $79 \%$ were satisfied with surgery, respectively. ${ }^{109}$

\section{Conclusion}

NERD is the most common phenotypic presentation of GERD. Whilst separating between erosive esophagitis and NERD on a clinical level is a very difficult task, there are clearly physiological, pathophysiological, anatomical, and even histological characteristics that are unique to NERD. Natural course studies demonstrate that most NERD patients will not progress over time to erosive esophagitis or even Barrett's oesophagus. NERD patients as compared to those with erosive esophagitis demonstrate a highly variable and unpredictable symptomatic response rate to antireflux treatment. This is likely to explain the high percentage of NERD patients among those who failed PPI treatment.

\section{References}

1. Fass R, Fennerty MB, Vakil N. Nonerosive reflux disease - current concepts and dilemmas. Am J Gastroenterol 2001;96:303-314.

2. Locke GR 3rd, Talley NJ, Fett SL, Zinsmeister AR, Melton LJ 3rd. Prevalence and clinical spectrum of gastroesophageal reflux: a population-based study in Olmsted County, Minnesota. Gastroenterology 1997;112:1448-1456.

3. Fass R, Sifrim D. Management of heartburn not responding to proton pump inhibitors. Gut 2009;58:295-309.

4. Fass R. Proton pump inhibitor failure--what are the therapeutic options? Am J Gastroenterol 2009;104(suppl 2):S33-S38.

5. Dent J, Brun J, Fendrick A, et al. An evidence-based appraisal of reflux disease management--the Genval Workshop Report. Gut 1999;44(suppl 2):S1-S16.

6. Vakil N, van Zanten SV, Kahrilas P, Dent J, Jones R. The Montreal definition and classification of gastroesophageal reflux disease: a global evidence-based consensus. Am J Gastroenterol 2006;101:1900-1920.

7. Martinez SD, Malagon IB, Garewal HS, Cui H, Fass R. Non-erosive reflux disease (NERD) - acid reflux and symptom patterns. Aliment Pharmacol Ther 2003;17:537-545.

8. Clouse RE, Richter JE, Heading RC, Janssens J, Wilson JA. Functional esophageal disorders. In: Drossman D, ed. Rome II: the functional gastrointestinal disorders. 2nd ed. Lawrence, KS: Allen Press, Inc., 2000:275.

9. Watson RG, Tham TC, Johnston BT, McDougall NI. Double blind cross-over placebo controlled study of omeprazole in the treatment of patients with reflux symptoms and physiological levels of acid reflux - the "sensitive oesophagus". Gut 1997;40:587-590.

10. Drossman D. Rome III: The functional gastrointestinal disorders. 3rd ed. McLean, VA: Degnon Associates, Inc., 2006:369-418.

11. Winters C Jr, Spurling TJ, Chobanian SJ, et al. Barrett's esophagus: A prevalent, occult complication of gastroesophageal reflux disease. Gastroenterology 1987;92:118-124.

12. Johansson KE, Ask P, Boeryd B, Fransson SG, Tibbling L. Oesophagitis, signs of reflux, and gastric acid secretion in patients with symptoms of gastro-oesophageal reflux disease. Scand J Gastroenterol 1986;21:837-847.

13. Lind T, Havelund T, Carlsson R, et al. Heartburn without oesophagitis: efficacy of omeprazole therapy and features determining therapeutic response. Scand J Gastroenterol 1997;32:974-979.

14. Jones RH, Hungin AP, Phillips J, et al. Gastro-esophageal reflux 
disease in primary care in Europe: clinical presentation and endoscopic findings. Eur J Gen Pract 1995;1:149-154.

15. Galmiche JP, Barthelemy P, Hamelin B. Treating the symptoms of gastro-oesophageal reflux disease: a double-blind comparison of omeprazole and cisapride. Aliment Pharmacol Ther 1997;11:765773.

16. Carlsson R, Dent J, Watts R, et al. Gastro-oesophageal reflux disease in primary care: an international study of different treatment strategies with omeprazole. International GORD Study Group. Eur J Gastroenterol Hepatol 1998;10:119-124.

17. Robinson M, Earnest D, Rodriguez-Stanley S, et al. Heartburn requiring frequent antacid use may indicate significant illness. Arch Intern Med 1998;158:2373-2376.

18. Ronkainen J, Aro P, Storskrubb T, et al. High prevalence of gastroesophageal reflux symptoms and esophagitis with or without symptoms in the general adult Swedish population: a Kalixanda study report. Scand J Gastroenterol 2005;40:275-285.

19. Zagari RM, Fuccio L, Wallander MA, et al. Gastro-oesophageal reflux symptoms, oesophagitis and Barrett's oesophagus in the general population: the Loiano-Monghidoro study. Gut 2008; 57:1354-1359.

20. Quigley EM. Gastro-oesophageal reflux disease - spectrum or continuum? QJM 1997;90:75-78.

21. Fass R. Erosive esophagitis and nonerosive reflux disease (NERD): comparison of epidemiologic, physiologic, and therapeutic characteristics. J Clin Gastroenterol 2007;41:131-137.

22. Fass R, Ofman J. Gastroesophageal reflux disease--should we adopt a new conceptual framework? Am J Gastroenterol 2002;97: 1901-1909.

23. Fass R. Non-erosive reflux disease (NERD) and erosive esophagitis--a spectrum of disease or special entities? Z Gastroenterol 2007;45:1156-1163.

24. Pace F, Santalucia F, Bianchi Porro G. Natural history of gastro-oesophageal reflux disease without oesophagitis. Gut 1991;32: 845-848.

25. Kuster E, Ros E, Toledo-Pimentel V, et al. Predictive factors of the long term outcome in gastro-oesophageal reflux disease: six year follow up of 107 patients. Gut 1994;35:8-14.

26. Isolauri J, Luostarinen M, Isolauri E, Reinikainen O, Viljakka M, Keyrilainen O. Natural course of gastroesophageal reflux disease: 17-22 year follow-up of 60 patients. Am J Gastroenterol 1997;92:37-41.

27. McDougall NI, Johnston BT, Kee F, Collins JS, McFarland RJ, Love AH. Natural history of reflux oesophagitis: a 10 year follow up of its effect on patient symptomatology and quality of life. Gut 1996;38:481-486.

28. McDougall NI, Johnston BT, Collins JS, McFarland RJ, Love $\mathrm{AH}$. Disease progression in gastro-oesophageal reflux disease as determined by repeat oesophageal $\mathrm{pH}$ monitoring and endoscopy 3 to 4.5 years after diagnosis. Eur J Gastroenterol Hepatol 1997; 9:1161-1167.

29. Manabe N, Yoshihara M, Sasaki A, Tanaka S, Haruma K, Chayama K. Clinical characteristics and natural history of patients with low-grade reflux esophagitis. J Gastroenterol Hepatol 2002;17:949-954.

30. Pace F, Bollani S, Molteni P, Bianchi Porro G. Natural history of gastro-oesophageal reflux disease without oesophagitis (NERD)--a reappraisal 10 years on. Dig Liver Dis 2004;36:111-115.

31. Pace F, Bianchi Porro G. Gastroesophageal reflux disease: a typical spectrum disease (a new conceptual framework is not needed). Am J Gastroenterol 2004;99:946-949.

32. Labenz J, Nocon M, Lind T, et al. Prospective follow-up data from the ProGERD study suggest that GERD is not a categorical disease. Am J Gastroenterol 2006;101:2457-2462.

33. Willich S, Nocon M, Kulig M, et al. Cost-of-disease analysis in patients with gastro-oesophageal reflux disease and Barrett's mucosa. Aliment Pharmacol Ther 2006;23:371-376.

34. Garrido Serrano A, Guerrero Igea FJ, Lepe Jiménez JA, Perianes Hernández C. Clinical features and endoscopic progression of gastroesophageal reflux disease. Rev Esp Enferm Dig (Madrid) 2003;95:712-716.

35. Sontag SJ, Sonnenberg A, Schnell TG, Leya J, Metz A. The long-term natural history of gastroesophageal reflux disease. J Clin Gastroenterol 2006;40:398-404.

36. Bardhan KD, Royston C, Nayyar AK. Reflux rising! An essay on witnessing a disease in evolution. Dig Liver Dis 2006;38:163-168.

37. Agrawal A, Castell D. GERD is chronic but not progressive. J Clin Gastroenterol 2006;40:374-375.

38. Ho KY, Kang JY. Reflux esophagitis patients in Singapore have motor and acid exposure abnormalities similar to patients in the Western hemisphere. Am J Gastroenterol 1999;94:1186-1191.

39. Martinez SD, Malagon I, Garewal HS, Fass R. Non-erosive reflux disease (NERD) - is it really just a mild form of gastroesophageal reflux disease (GERD) [abstract]? Gastroenterology 2001; 120(suppl 1):A424.

40. Shapiro M, Green C, Faybush EM, Esquivel RF, Fass R. The extent of oesophageal acid exposure overlap among the different gastro-oesophageal reflux disease groups. Aliment Pharmacol Ther 2006;23:321-329.

41. Dickman R, Bautista JM, Wong WM, et al. Comparison of esophageal acid exposure distribution along the esophagus among the different gastroesophageal reflux disease (GERD) groups. Am J Gastroenterol 2006;101:2463-2469.

42. Adachi K, Fujishiro H, Katsube T, et al. Predominant nocturnal acid reflux in patients with Los Angeles grade C and D reflux esophagitis. J Gastroenterol Hepatol 2001;16:1191-1196.

43. Dickman R, Parthasarathy S, Malagon IB, et al. Comparisons of the distribution of oesophageal acid exposure throughout the sleep period among the different gastro-oesophageal reflux disease groups. Aliment Pharmacol Ther 2007;26:41-48.

44. Bredenoord AJ, Weusten BL, Curvers WL, Timmer R, Smout AJ. Determinants of perception of heartburn and regurgitation. Gut 2006;55:313-318.

45. Emerenziani S, Sifrim D, Habib FI, et al. Presence of gas in the refluxate enhances reflux perception in non-erosive patients with physiological acid exposure of the oesophagus. Gut 2008; 57:443-447.

46. Schey R, Shapiro M, Navarro-Rodriguez T, et al. Comparison of the different characteristics of sensed reflux events among different heartburn groups. J Clin Gastroenterol 2009;43:699-704.

47. Emerenziani S, Ribolsi M, Sifrim D, Blondeau K, Cicala M. Regional oesophageal sensitivity to acid and weakly acidic reflux in 
patients with non-erosive reflux disease. Neurogastroenterol Motil 2009;21:253-258.

48. Savarino E, Zentilin $\mathrm{P}$, Tutuian $\mathrm{R}$, et al. The role of nonacid reflux in NERD: lessons learned from impedance-pH monitoring in 150 patients off therapy. Am J Gastroenterol 2008;103:2685-2693.

49. Farre R, Fornari F, Blondeau K, et al. Acid and weakly acidic solutions impair mucosal integrity of distal exposed and proximal non-exposed human oesophagus. Gut 2010 (In press)

50. Vaezi MF, Richter JE. Role of acid and duodenogastroesophageal reflux in gastroesophageal reflux disease. Gastroenterology 1996; 111:1192-1199.

51. Iwakiri K, Hayashi Y, Kotoyori M, et al. Defective triggering of secondary peristalsis in patients with non-erosive reflux disease. $\mathrm{J}$ Gastroenterol Hepatol 2007;22:2208-2211.

52. Cameron AJ. Barrett's esophagus: prevalence and size of hiatal hernia. Am J Gastroenterol 1999;94:2054-2059.

53. van Herwaarden MA, Samsom M, Smout AJ. Excess gastroesophageal reflux in patients with hiatus hernia is caused by mechanisms other than transient LES relaxations. Gastroenterology 2000;119:1439-1446.

54. Dent J. Microscopic esophageal mucosal injury in nonerosive reflux disease. Clin Gastroenterol Hepatol 2007;5:4-16.

55. Mastracci L, Grillo F, Zentilin P, et al. Cell proliferation of squamous epithelium in gastro-oesophageal reflux disease: correlations with clinical, endoscopic and morphological data. Aliment Pharmacol Ther 2007;25:637-645.

56. Knowles $\mathrm{CH}, \mathrm{Aziz} \mathrm{Q}$. Visceral hypersensitivity in non-erosive reflux disease. Gut 2008;57:674-683.

57. Miwa H, Minoo T, Hojo M, et al. Oesophageal hypersensitivity in Japanese patients with non-erosive gastro-oesophageal reflux diseases. Aliment Pharmacol Ther 2004;20(suppl 1):112-117.

58. Nagahara A, Miwa H, Minoo T, et al. Increased esophageal sensitivity to acid and saline in patients with nonerosive gastro-esophageal reflux disease. J Clin Gastroenterol 2006;40:891-895.

59. Shapiro M, Green C, Bautista JM, et al. Functional heartburn patients demonstrate traits of functional bowel disorder but lack a uniform increase of chemoreceptor sensitivity to acid. Am J Gastroenterol 2006;101:1084-1091.

60. Thoua NM, Khoo D, Kalantzis C, Emmanuel AV. Acid-related oesophageal sensitivity, not dysmotility, differentiates subgroups of patients with non-erosive reflux disease. Aliment Pharmacol Ther 2008;27:396-403.

61. Reddy H, Staahl C, Arendt-Nielsen L, Gregersen H, Drewes AM, Funch-Jensen P. Sensory and biomechanical properties of the esophagus in non-erosive reflux disease. Scand J Gastroenterol 2007;42:432-440.

62. Trimble KC, Pryde A, Heading RC. Lowered oesophageal sensory thresholds in patients with symptomatic but not excess gastro-oesophageal reflux: evidence for a spectrum of visceral sensitivity in GORD. Gut 1995;37:7-12.

63. Bhat YM, Bielefeldt K. Capsaicin receptor (TRPV1) and non-erosive reflux disease. Eur J Gastroenterol Hepatol 2006;18:263-270.

64. Sarkar S, Hobson AR, Hughes A, et al. The prostaglandin E2 receptor-1 (EP-1) mediates acid-induced visceral pain hypersensitivity in humans. Gastroenterology 2003;124:18-25.

65. Anand P, Aziz Q, Willert R, van Oudenhove L. Peripheral and central mechanisms of visceral sensitization in man. Neurogastroenterol Motil 2007;19:29-46.

66. Fass R, Naliboff BD, Fass SS, et al. The effect of auditory stress on perception of intraesophageal acid in patients with GERD. Gastroenterology 2008;134:696-705.

67. Schey R, Dickman R, Parthasarathy S, et al. Sleep deprivation is hyperalgesic in patients with gastroesophageal reflux disease. Gastroenterology 2007;133:1787-1795.

68. Fass R, Tougas G. Functional heartburn: the stimulus, the pain, and the brain. Gut 2002;51:885-892.

69. Barlow WJ, Orlando RC. The pathogenesis of heartburn in nonerosive reflux disease: a unifying hypothesis. Gastroenterology 2005;128:771-778

70. Ang D, Sifrim D, Tack J. Mechanisms of heartburn. Nat Clin Pract Gastroenterol Hepatol 2008;5:383-392.

71. Lind T, Havelund T, Lundell L, et al. On demand therapy with omeprazole for the long-term management of patients with heartburn without oesophagitis - a placebo-controlled randomized trial. Aliment Pharmacol Ther 1999;13:907-914.

72. Hampel H, Abraham NS, El-Serag HB. Meta-analysis: obesity and the risk of gastroesophageal reflux disease and its complications. Ann Intern Med 2005;143:199-211.

73. Aro P, Ronkainen J, Talley NJ, Storskrubb T, Bolling-Sternevald $\mathrm{E}$, Agreus L. Body mass index and chronic unexplained gastrointestinal symptoms: an adult endoscopic population based study. Gut 2005;54:1377-1383.

74. Lee YC, Yen AM, Tai JJ, et al. The effect of metabolic risk factors on the natural course of gastro-oesophageal reflux disease. Gut 2009;58:174-181.

75. Mayer EA. The neurobiology of stress and gastrointestinal disease. Gut 2000;47:861-869.

76. Richter JE, Bradley LC. Psychophysiological interactions in esophageal diseases. Semin Gastrointest Dis 1996;7:169-184.

77. Nielzen S, Pettersson KI, Regnell G, Svensson R. The role of psychiatric factors in symptoms of hiatus hernia or gastric reflux. Acta Psychiatr Scand 1986;73:214-220.

78. Lee YC, Wang HP, Chiu HM, et al. Comparative analysis between psychological and endoscopic profiles in patients with gastroesophageal reflux disease: a prospective study based on screening endoscopy. J Gastroenterol Hepatol 2006;21:798-804.

79. Wu JC, Cheung CM, Wong VW, Sung JJ. Distinct clinical characteristics between patients with nonerosive reflux disease and those with reflux esophagitis. Clin Gastroenterol Hepatol 2007;5: 690-695.

80. Kahrilas PJ, Miner P, Johanson J, Mao L, Jokubaitis L, Sloan S. Efficacy of rabeprazole in the treatment of symptomatic gastroesophageal reflux disease. Dig Dis Sci 2005;50:2009-2018.

81. Zimmerman J, Hershcovici T. Bowel symptoms in nonerosive gastroesophageal reflux disease: nature, prevalence, and relation to acid reflux. J Clin Gastroenterol 2008;42:261-265.

82. Hershcovici T, Zimmerman J. Functional heartburn vs. non-erosive reflux disease: similarities and differences. Aliment Pharmacol Ther 2008;27:1103-1109.

83. Smout AJPM. Endoscopy-negative acid reflux disease. Aliment Pharmacol Ther 1997;11:81-85.

84. Venables TL, Newland RD, Patel AC, Hole J, Wilcock C, Turbitt 
ML. Omeprazole 10 milligrams once daily; omeprazole $20 \mathrm{mg}$ milligrams once daily, or ranitidine 150 milligrams twice daily, evaluated as initial therapy for the relief of symptoms of gastro-oesophageal reflux disease in general practice. Scand J Gastroenterol 1997;32:965-973.

85. Yi CH, Hu CT, Chen CL. Sleep dysfunction in patients with GERD: erosive versus nonerosive reflux disease. Am J Med Sci 2007;334:168-170.

86. Kiesslich R, Kanzler S, Vieth M, et al. Minimal change esophagitis: prospective comparison of endoscopic and histological markers between patients with non-erosive reflux disease and normal controls using magnifying endoscopy. Dig Dis 2004;22:221-227.

87. Yoshikawa I, Yamasaki M, Yamasaki T, Kume K, Otsuki M. Lugol chromoendoscopy as a diagnostic tool in so-called endoscopy-negative GERD. Gastrointest Endosc 2005;62:698-703.

88. Sharma P, Wani S, Bansal A, et al. A feasibility trial of narrow band imaging endoscopy in patients with gastroesophageal reflux disease. Gastroenterology 2007;133:454-464.

89. Lee YC, Lin JT, Chiu HM, et al. Intraobserver and interobserver consistency for grading esophagitis with narrow-band imaging. Gastrointest Endosc 2007;66:230-236.

90. Nakamura T, Shirakawa K, Masuyama H, Sugaya H, Hiraishi H, Terano A. Minimal change oesophagitis: a disease with characteristic differences to erosive oesophagitis. Aliment Pharmacol Ther 2005;21:19-26.

91. Spechler SJ, Genta RM, Souza RF. Thoughts on the complex relationship between gastroesophageal reflux disease and eosinophilic esophagitis. Am J Gastroenterol 2007;102:1301-1306.

92. Dellon ES, Gibbs WB, Fritchie KJ, et al. Clinical, endoscopic, and histologic findings distinguish eosinophilic esophagitis from gastroesophageal reflux disease. Clin Gastroenterol Hepatol 2009;7: 1305-1313.

93. Fass R, Ofman J, Gralnek I, et al. Clinical and economic assessment of the omeprazole test in patients with symptoms suggestive of gastroesophageal reflux disease. Arch Intern Med 1999;159:21612168.

94. Gasiorowska A, Fass R. The proton pump inhibitor (PPI) test in GERD: does it still have a role? J Clin Gastroenterol 2008; 42:867-874.

95. Fass R, Gasiorowska A. Refractory GERD: what is it? Curr Gastroenterol Rep 2008;10:252-257.

96. Mainie I, Tutuian R, Shay S, et al. Acid and non-acid reflux in patients with persistent symptoms despite acid suppressive therapy: a multicentre study using combined ambulatory impedance-pH monitoring. Gut 2006;5 5:1398-1402.

97. van Pinxteren B, Numans ME, Bonis PA, Lau J. Short-term treatment with proton pump inhibitors, $\mathrm{H}_{2}$-receptor antagonists and prokinetics for gastro-oesophageal reflux disease-like symptoms and endoscopy negative reflux disease. Cochrane Database Syst Rev 2004;18:CD002095.

98. Bate CM, Griffin SM, Keeling PW, et al. Reflux symptom relief with omeprazole in patients without unequivocal oesophagitis. Aliment Pharmacol Ther 1996;10:547-555.

99. Miner P Jr, Orr W, Filippone J, Jokubaitis L, Sloan S. Rabeprazole in nonerosive gastroesophageal reflux disease: a randomized placebo-controlled trial. Am J Gastroenterol 2002;97:1332-1339.

100. Calabrese C, Liguori G, Gabusi V, et al. Ninety-six-hour wireless oesophageal $\mathrm{pH}$ monitoring following proton pump inhibitor administration in NERD patients. Aliment Pharmacol Ther 2008;28: 250-255.

101. Dean BB, Gano AD Jr, Knight K, Ofman JJ, Fass R. Effectiveness of proton pump inhibitors in nonerosive reflux disease. Clin Gastroenterol Hepatol 2004;2:656-664.

102. Richter JE, Campbell DR, Kahrilas PJ, Huang B, Fludas C. Lansoprazole compared with ranitidine for the treatment of nonerosive gastroesophageal reflux disease. Arch Intern Med 2000;160:1803-1809.

103. Monnikes H, Pfaffenberger B, Gatz G, Hein J, Bardhan KD. Novel measurement of rapid treatment success with ReQuest: first and sustained symptom relief as outcome parameters in patients with endoscopy-negative GERD receiving $20 \mathrm{mg}$ pantoprazole or $20 \mathrm{mg}$ esomeprazole. Digestion 2005;71:152-158.

104. Bytzer P, Blum A, De Herdt D, Dubois D. Six-month trial of on-demand rabeprazole $10 \mathrm{mg}$ maintains symptom relief in patients with non-erosive reflux disease. Aliment Pharmacol Ther 2004; 20:181-188.

105. Juul-Hansen P, Rydning A. On-demand requirements in patient with endoscopy-negative GERD: $\mathrm{H}_{2}$-blocker versus PPI. Aliment Pharmacol Ther 2009;29:207-212.

106. Wiklund I, Bardhan KD, Muller-Lissner S, et al. Quality of life during acute and intermittent treatment of gastro-oesophageal reflux disease with omeprazole compared with ranitidine. Results from a multicentre clinical trial. The European Study Group. Ital J Gastroenterol Hepatol 1998;30:19-27.

107. Gerson LB, Robbins AS, Garbert A, Hornberger J, Triadafilopoulas G. A cost-effectiveness analysis of prescribing strategies in the management of gastroesophageal reflux disease. Am J Gastroenterol 2000;95:395-407.

108. Fass R, Chey WD, Zakko SF, et al. Clinical trial: the effects of the proton pump inhibitor dexlansoprazole MR on daytime and nighttime heartburn in patients with non-erosive reflux disease. Aliment Pharmacol Ther 2009;29:1261-1272.

109. Fenton P, Terry ML, Galloway KD, Smith CD, Hunter JG, Waring JP. Is there a role for laparoscopic fundoplication in patients with non-erosive reflux disease (NERD) [abstract]? Gastroenterology 2000;118(suppl 2):A481. 